\title{
Linguagem, corpo, estética e experiência - (re)dimensionamento do sentido e da presença nas práticas comunicativas midiatizadas
}

\author{
Gisele Miyoko Onuki \\ https://orcid.org/0000-0002-1507-4534 \\ Cristiane Wosniak' \\ https://orcid.org/0000-0002-7234-2638 \\ I - UNESPAR \\ Curitiba (PR), Brasil
}

Resumo: Como seria possível qualificar as experiências vividas e percepções da realidade? Dentre as diversas variações históricas espaço-temporais (BARBOSA, 2012; KOSELLECK, 2006) que constituem as transformações culturais de experiências, percepções e ações que regem nosso tempo presente, bem como projetam expectativas quanto ao devir da cultura e da sociedade, esta pesquisa visa refletir sobre a edificação da sensibilidade sob a perspectiva das oscilações da experiência do real para uma possível qualificação dos sentidos. Para tanto, parte-se da hipótese de que o homem contemporâneo é acometido por uma "crise da experiência" (BENJAMIN, 1975) que redireciona a dimensão de sentido e presença (GUMBRECHT, 2010, 2015) nos agenciamentos das práticas comunicativas midiatizadas (HEPP; HASEBRINK, 2015), culminando nos modos de (in)tangenciar a realidade, (re)confingurando as mediações culturais e sociais.

Palavras-chave: temporalidade; acontecimento; experiência; corpo; presença.

Abstract: The Body and the Crisis of Experience - (Re)Sizing Meaning and Presence in Mediated

Communicative Practices - How could one qualify lived experiences and perceptions of reality? Among the various spatio-temporal historical variations (BARBOSA, 2012; KOSELLECK, 2006) that constitute the cultural transformations of experiences, perceptions 
and actions that govern our present time, as well as projecting expectations as to the coming into being of culture and society, this research aims to reflect on the construction of the sensibility from the perspective of the oscillations of the experience of the real to a possible qualification of the senses. In order to do so, it is assumed that contemporary man is affected by a "crisis of experience" (BENJAMIN, 1975) that redirects the dimension of meaning and presence (GUMBRECHT, 2010, 2015) in the mediated communicative practices (HEPP; HASEBRINK, 2015), culminating in the ways of (in)tangentiating reality, (re)configuring cultural and social mediations.

Keywords: temporality; event; experience; body; presence.

Pensar o corpo é outra maneira de pensar o mundo. (DAVID LE BRETON, 2016)

\section{Introdução}

A partir do pensamento contemplado na epígrafe e imbuída pela curiosidade de compreender um crescente reflexo social sobre os gatilhos que desencadeiam as emoções e afetividades nas sociedades midiatizadas (HEPP, 2014), esta investigação, de caráter reflexivo, tem por objetivo encontrar caminhos para compreender as metamorfoses do sensível e a constituição de experiências e expectativas quanto ao viver na sociedade contemporânea, mediante o paradoxo da existência humana que desencadeia um estado de crescente solidão promovida pelas relações efêmeras de configurações artificiais.

Tal como a brisa que preenche os espaços vazios e adentra o ambiente pela pequena fresta da janela e faz a cortina suspirar, buscaremos situar a emergência do viver contemporâneo e realocá-lo na potência do vazio para assim tornar possível o desvelamento da graciosidade como forma de resgatar a experiência vivida do humano e prover expectativas (KOSELLECK, 2006) em tempo de crise da percepção que culminam nos modos de (in)tangenciar a realidade, (re)confingurando as mediações culturais e sociais.

Em sua obra intitulada Futuro Passado ([1979] 2006), Reinhart Koselleck formatou sua singular perspectiva historicista sobre as constantes alterações na sensibilidade humana diante do tempo, ao considerar que cada presente não apenas reconstrói o passado a partir de problematizações geradas na sua atualidade, mas também de que cada presente ressignifica tanto o passado - denominado 'campo da experiência'; como o futuro denominado 'horizonte de expectativas'.

Na tentativa de conectar passado e futuro, o presente se constitui, segundo Koselleck (2006), através de duas categorias que se tencionam e se materializam no presente a experiência e a expectativa.

Experiência também é um dos termos utilizados por Raymond Williams ([1969] 2011), para definir e compreender a Cultura como um organismo vivo em constante transformação, que se atualiza e redefine os significados culturais no percurso 
de transformar a história sociocultural em experiência vivida, do pessoal ao coletivo. Esta seria a base que sustenta uma das noções de 'Estruturas de Sentimento' cunhada por Williams - a Cultura é percebida ao longo de um processo e se auto-ressignifica através dos fenômenos que, segundo Clifford Geertz ([1989] 2011), constituem uma teia de significados e a "experiência humana é construída dentro de estruturas simbólicas" (GEERTZ, 2011, p. 179).

Neste viés, Hans Ulrich Gumbrecht posiciona a consciência histórica como "forma de experiência" e, como Edmund Husserl definiu: "uma construção social do tempo, que determina como transformamos as mudanças que captamos no nosso ambiente numa relação que estabelecemos conosco e com as nossas ações" (apud GUMBRECHT, 2015, p. 67).

Dentre as diversas variações históricas espaço-temporais que constituem as transformações culturais de experiências, percepções e ações que regem nosso tempo presente, bem como projetam expectativas quanto ao devir da cultura e do humano, Marialva Carlos Barbosa lança a importância do olhar historiográfico para apresentar a comunicação "como o lugar do poder, o lugar do saber e o lugar simbólico" (BARBOSA, 2012, p. 146), ao atribuir o lugar de fala ao sujeito do processo enunciativo de produção de sentido e presença (GUMBRETCH, 2010).

Norval Baitello Junior (2014, p. 12), por sua vez, afirma que o corpo é o "primeiro suporte dos textos culturais e dos processos comunicativos, como 'mídia primária'", isto porque a abrangência dos fenômenos comunicacionais como processos culturais e históricos estabelecem uma relação direta entre corpos.

Todavia, pesquisas sobre as 'configurações comunicativas' apontam análises pautadas na (inter)-ação entre seres humanos e a pesquisa em "midiatização, então, passa a se preocupar com a maneira com a qual essa interação social muda quando meios técnicos de comunicação se tornam parte dela" (HEPP; HASEBRINK, 2015, p. 77).

Considera-se que novas tecnologias (mídias) e suas relações de afetividade com o corpo ganharam novas dinâmicas na contemporaneidade. Estas dinâmicas refletem as dimensões e características das materialidades e sensibilidades do sujeito contemporâneo e, consequentemente, de seus modos de assimilar as experiências e assim compreender o mundo no qual vive, em suas oscilações de percepção da realidade.

Baitello Junior indaga se a relação entre mídia e sujeito não estaria por provocar, aos poucos, a perda das sensações do próprio corpo e de seu espaço-tempo, no que denominou de 'perda da percepção' e 'perda do presente'.

Para o autor:

O primeiro aspecto [perda da percepção] traz consigo uma crise no regime da visibilidade, uma vez que toda hipertrofia gera a distrofia compensatória. Quanto mais imagens, menos visibilidade, e quanto mais visão, menos propriocepção, o sentido por excelência do aqui e agora, da corporeidade. O segundo aspecto 
traz consigo a perda do presente, pois tantos tempos presentes se apresentam em um curto tempo, sem que cada um deles tenha a oportunidade de se tornar ato, apenas remetendo para o outro, subentendendo e exigindo a rápida passagem em zapping para o próximo (BAITELLO JUNIOR, 2014, p. 61).

Walter Benjamin ([1939] 1975), ao apresentar suas reflexões sobre o século XIX, desenvolve sua teoria da modernidade e suas implicações com base nas transformações históricas pautadas na economia e nas mudanças dos modos de produção, que culminam na chamada "crise da experiência", impulsionada por uma nova forma de perceber o mundo.

Em seu ensaio Sobre alguns temas em Baudelaire, Benjamin ([1939] 1975) estrutura a verdadeira experiência (Erfahrung) como sendo uma atividade condicionada à rememoração. Rememoração é considerada a reiteração do reencontro do passado e do presente e é neste reencontro que se estrutura a experiência, por uma relação articulada pelo distanciamento do esquecimento com a rememoração, da formação da memória individual ao coletivo e vice-versa.

Todavia, a crise da experiência é promovida pela dissolução dos modos de assimilar a experiência que projetam no homem a vontade de buscar uma experiência plena, do ideal, do memorável, porém de uma natureza, por vezes, irreal.

Esta perspectiva nos leva a considerar algumas premissas que desencadeiam na experiência da 'realidade' confrontada com noções de 'verdade'.

Gumbrecht (2012), distingue quatro premissas que amparam a compreensão de realidade e verdade, sendo: 1) A 'evidência momentânea' - Experiência da realidade marcada por uma intuição infalível de certeza; 2) A realidade 'garantida' por Deus e frequentemente reconstruída por intrincadas deduções do pensamento; 3) O 'contexto coerente' a qual se consideravam reais todas as experiências que se conformassem com um mundo que se considerasse já apreendido; 4) Conceito de realidade que se constitui na 'experiência residencial'.

Segundo Gumbrecht,

Os conceitos de 'realidade' e 'verdade' apartaram-se de tal forma que, dessa divergência, pôde surgir um pathos específico do real. Pois quando só se alcança o real indiretamente como 'resistência' ou, por assim dizer, 'sintomaticamente' mediante a impressão de que não se ajusta às possibilidade humanas de conhecimento, a esperança de dominar a realidade ainda não se apagou definitivamente, mas certamente a esperança de verdade como contemplação do real $(2012$, p. 79$)$.

Deste modo, a capacidade ou habilidade de perceber e viver reside no nível de sensibilidade e percepção que o sujeito possui dele mesmo enquanto um 'ser-no-mundo' e um 'ser-do-mundo', através da consciência de tangenciar o real ou não, transpondo verdades e acontecimentos para reconfigurar seu tempo presente. 
Entre as oscilações que constituem a experiência, de um lado o cotidiano e do outro as materializações do presente, em seus estudos mais recentes, Gumbrecht (2015), apresenta quatro perspectivas fragmentárias do que vem identificando de 'nosso amplo presente'. Para o autor, o amplo presente consiste nas seguintes oscilações: 1) O 'conhecimento' partilhado está sempre sob suspeita de ser mera 'construção social da realidade', o que sugere que é sempre impossível chegar ao que é 'realmente real'; 2) Retorno dos direitos e cuidados corpóreos definitivos que concedem uma posição de relevância epistemológica ao próprio sujeito; 3) A existência humana enquanto condição exclusiva do corpo do indivíduo como um lugar de poder; 4) Reconfiguração do pensamento e seus modos de circulação.

Assim como Baitello Junior (2014), Gumbrecht (2015), sintetiza a emergência do tempo presente pautada no desenvolvimento do corpo e de seu ser nas nuances espaçotemporais e construções históricas da sensibilidade e da experiência, seja ela percebida ou vivida. Todavia, ambos também concordam com um crescente fluxo operacional que projeta no humano (ou é desenvolvido por) outro fluxo crescente que é a vontade de 'perder-se de si' e de 'desaparecer de si', embalados por diversas crises que o acometem na contemporaneidade.

\section{Corpo e (m) Crise... Como se desvencilhar?}

David Le Breton em seu mais recente livro intitulado Desaparecer de sí: Una tentación contemporânea (2016a), aborda as diversas formas e desejos do homem contemporâneo em suspender-se através de um estado particular de anulação, ao tentar ausentar-se espaçotemporalmente do tecido social e de si próprio, como uma tentativa de fuga estratégica para recompor-se do ritmo frenético imposto pelas sociedades midiatizadas (HEPP, 2014).

Em um cotidiano marcado por exigências e imersos em um mundo desterritorializado, onde as barreiras do tempo e do espaço comunicacional deixam de existir perante o imperialismo do sentido, da conectividade full-time e da máxima performance, consideramos que muitos indivíduos frustram-se ao se depararem imersos em um universo de opressão racional e constatarem significativa perda de suas singularidades e, consequentemente, de deslumbramentos estéticos que culminam no desaparecimento de suas essências.

Segundo Haroche (2009, p. 211), vivemos uma modificação radical dos modos de ser, sentir e perceber as sociedades contemporâneas, observados os efeitos fundamentais da mídia que consiste "em engajar e desenvolver uma cultura dos sentidos e sensações, por intermédio de estímulos, e em controlar a alternância entre a capacidade de atenção e de desatenção."

Considera-se que é exatamente neste fluxo de estímulos artificiais que se produzem as mais diversas formas de alienação, dentre elas, adquire-se a incapacidade de sentir e perceber - atrofia sensorial, levando ao automatismo do viver, provocando a "apatia e inércia, e provocando o cansaço do eu" (HAROCHE, 2009, p. 204). 
Diante deste esgotamento gerado pelo cotidiano, Le Breton (2016a) aponta uma crescente tentação dos indivíduos de desaparecerem de si mesmos.

De maneira temporária ou duradoura, a busca pela ausência encontra em si paradoxos relativistas da próxima existência, tal como descreve Clarice Lispector sobre a experiência de G.H. - "A alegria de perder-se é uma alegria de sabá. Perder-se é um achar-se perigoso." (2009, p. 101), ou como cita Le Breton: "Hacerse el muerto es una manera de cambiar y no morir, de evitar matarse incluso"1 (2016a, p. 18), são alegorias a serem resolvidas por caminhos não lógicos, tendo em vista que o efeito de presença destes paradoxos, em determinados momentos, permitem transmitir justamente aquilo que os sentidos não conseguem pela linguagem racional, que é expressar uma experiência e ser assimilado pelo nível da intuição.

Todavia, intuição implica em níveis de sensação e percepção, que são processos capazes de despertar afetividade e afeto como um marco do ato sensitivo.

Para tanto, cabe distinguirmos estes dois elementos tão complementares, mas diversos: "A sensação e a percepção compreendem processos biológicos e psicológicos distintos que nos permitem conhecer a realidade." (RIES, 2004, p. 49).

A sensação é tomada como um fenômeno psíquico que resulta da ação de estímulos externos e internos sobre os nossos órgãos dos sentidos. É o processo que qualifica os feitos e os converte em sensações. Logo, a percepção é um fenômeno mais complexo que compreende a capacidade de interpretação dos efeitos advindos das sensações.

Segundo Bruno Ries (2004), a percepção é singular e personalizada, a qual as questões afetivas afetam diretamente as dinâmicas interpretativas do sujeito.

Ao depreender a percepção pelo viés dos postulados de Charles Sanders Peirce, referente à Teoria da Percepção e à Teoria Geral dos Signos, Lúcia Santaella (1998) nos assegura que em termos lógicos, ontológicos e epistemológicos, nenhuma outra teoria da percepção se mostrou tão apta quanto os estudos de Peirce a eliminar a lacuna entre o sensório e a mente. Segundo Santaella "não há, nem pode haver, separação entre percepção e conhecimento [...] todo pensamento lógico, toda cognição, entra pela porta da percepção e sai pela porta da ação deliberada." (SANTAELLA, 1998, p. 16).

Reflete a autora:

Sendo a teoria dos signos também uma teoria do conhecimento, não poderia faltar a essa teoria uma teoria da percepção, visto que é justamente a percepção que vai desempenhar o papel de ponte de ligação entre o mundo da linguagem, o cérebro, e o mundo lá fora. A percepção corresponde, assim, ao lado mais ontológico e também psicológico da semiótica (SANTAELLA, 1998, p. 14).

Deste modo, a autora apresenta os argumentos de Peirce para melhor compreender a percepção: a) Percepto - aquilo que se apresenta e que está fora de nós. É algo que

\footnotetext{
1 "Fingir-se de morto é uma maneira de mudar e não morrer, de evitar o suicídio inclusive." (Tradução nossa).
} 
se apresenta sem rótulos, mas com potência para estimular a percepção. O percepto é acolhido pela mente interpretadora e converte-se em percipuum; b) Percipuum é o modo pelo qual o percepto está representado no juízo perceptivo. Apresenta-se como um filtro adaptado à sobrevivência e limita-se ao mundo sensorial; c) Juízo Perceptivo - é o julgamento de percepção ou juízo perceptivo que indicará aquilo que está sendo interpretando e percebido.

Destarte, podemos afirmar que se constituem em signos tanto o sujeito, quanto a consciência e o pensamento deste mesmo sujeito. Como afirma Santaella em Percepção: fenomenologia, ecologia, semiótica (2012, p. 116) "o sujeito é signo."

Pela perspectiva da semiótica da percepção apresentada, podemos inferir que o encontro salutar entre o sensível e o inteligível desencadeia elementos altamente indiciais, corpóreos que, segundo Jean-Luc Nancy (2014), reside no instante do movimento-entre do toque.

O toque, enquanto ato e potência em si, abre o corpo ao universo da aisthêsis e o funda numa relação estética com o mundo pelo viés da experiência e da afetividade.

Isto porque a ciência das sensações, como reflete Carole Talon-Hugon (2009), sobre a definição do campo de estudo da estética proposto por Paul Valéry (1937), devem fundamentalmente,

analisar como é que elas [as sensações], na dimensão afectiva e não só cognitiva, tocam misteriosamente na inteligência, na sensibilidade e na acção, e de que modo proporcionam um prazer desligado da necessidade, que excede a sensorialidade e em que se misturam voluptuosidade, fecundidade e energia. (TALON-HUGON, 2009, p. 99 - grifo nosso).

O toque não se trata de uma metáfora, mas de uma realidade sensível e material, pois este é o "único sentido indispensável à vida, o tato constitui-se em fonte originária da relação do homem com o mundo" (LE BRETON, 2016b, p. 206). De todo modo, esta relação se manifesta no e pelo movimento, pois o ato de mover enfatiza justamente que a condição humana se processa pelo corpo, ou seja, que a condição humana de apreender o mundo se instaura através daquilo que lhe toca e consequentemente sente e atribui sentido à sua existência.

Em uma sociedade regida pela supremacia do olhar e da audição, fruto do anseio pela ubiquidade das subjetividades e da virtualização do self, a potência da inibição do ato de mover ceifa do homem suas capacidades sensitivas e perceptivas, sendo que, ao lhe atribuir o automatismo de viver, o "homem deixa de ser um cidadão dotado de consciência e de vontade. Ele deixou de pensar para ser pensado. [...] Ele deixou de querer" (SANTIN, 1990, p. 16).

O desabafo de Santin permeia as diferentes abordagens sobre o corpo, atreladas a definições e análises que muitas vezes possuem implicações com base na tendência cartesiana, projetando metáforas e atos comunicativos através da constante busca do corpo por um 'lugar central' no tempo-espaço. 
Observa-se que muitas questões sobre o anseio do sujeito de ausentar-se de si mesmo na contemporaneidade desencadeiam respostas atreladas aos avanços científicos, tecnológicos e capitalistas, que projetam a emanação de diversas problematizações em torno do corpo, especialmente por transformarem continuamente os modos de ser, pensar e sentir do sujeito, culminando numa certa inabilidade da faculdade de julgar (FERRY, 2009), ao tornar superficial as relações consigo e com o seu entorno. A este processo de superficialidade, denominamos de crise da percepção.

\section{Crise(s) do Sujeito Contemporâneo: a potência do vazio e a experiência estética}

Além das diferentes formas de crise do sujeito que implicam em mudanças e transformações da e na sociedade contemporânea ou como identifica Andreas Hepp e Uwe Hasebrink (2015) - sociedades midiatizadas, haveria ainda alguma outra a se considerar?

Um caminho possível para nos desvencilharmos da crise da percepção, nesta investigação reflexiva, desenha-se através de uma concepção holística de compreender as lógicas do cotidiano, apresentado pela cultura japonesa por meio do conceito de ' $M a^{\prime}$ (間). 'Ma' é considerado um modus operandi que se apresenta em todos os aspectos da cultura japonesa na qual a construção do conhecimento se processa mais pela percepção do que pelas lógicas rígidas da razão ocidental.

Para melhor compreendermos o conceito de ' $\mathrm{Ma}^{\prime}$, faz-se necessário interpretar sua escrita. O ideograma 'Ma' é a combinação de dois caracteres - 門 (kadou - porta/portal) e 日 (hi - sol), que traz em sua semântica a noção de mediação, mas também de uma forma que implica na multi-sensorialidade, de um espaço 'entre'. Da união destes caracteres temos 閒 (ma, aida, kan), que pode significar 'entre-espaço', 'espaço intermediário', 'intervalo' ou 'vazio'.

A ideia de vazio em 'Ma' é tida como um vazio com propósito, pois possui conteúdo e significado. Um significado que se expressa na inexistência de algo, ou seja, é uma ausência a qual se permite que algo se manifeste através dela no tempo e no espaço. Conforme observamos no ideograma de 'Ma', uma porta aberta representa um vão, um vazio e é através deste vazio que é possível perceber os elementos que por ela perpassam e se manifestam, tal como a brisa, a luz do sol, o som do vento, entre outros.

Segundo Arata Isozaki, citado por Walkyria Coutinho,

No Japão, os conceitos de espaço e tempo têm sido simultaneamente apreendidos pela única palavra 'Ma'. Ma é, literalmente, definido como o intervalo natural entre duas ou mais coisas existentes em uma continuidade ' $\mathrm{ou}^{\prime}$ ' o fosso entre duas coisas, uma abertura; o espaço abrangido por colunas ou biombos ou a pausa singular ou intervalo em que os fenômenos surgem ao longo do tempo (ARATA ISOZAKI apud COUTINHO, 2009, p. 156). 
Por sua vez, Michiko Okano apresenta a concepção de 'Ma' como uma possibilidade, defendida através da lógica do 'terceiro excluído' de Aristóteles:

o Ma, enquanto possibilidade, associa-se ao "vazio", que, distinto de uma concepção ocidental cujo significado é o nada, é visto como algo do nível da potencialidade, que tudo pode conter, e, portanto, da possibilidade de geração do novo. É, por conseguinte, o vazio da disponibilidade de nascimento de algo novo e não da ausência e da morte (OKANO, 2014, p. 151).

De certo modo, o resgaste do sujeito imerso na crise da percepção contemporânea pode encontrar 'bolhas de oxigênio' ao permitir que espaços se abram em seu cotidiano advindo de 'pausas' e momentos de contemplação do 'vazio' para assim ser capaz de reencontrar seu senso de equilíbrio ao despertar o retorno da atenção para si por meio de experiências que promovam de forma completa e complexa um reencontro consigo mesmo, que possibilite seu (re)encontro com sensações e percepções singulares, advindas da reativação e aquisição de memórias sensoriais, corporais e psíquicas.

Nesta analogia, tomamos os escritos de Heinrich von Kleist (2016), em seu célebre ensaio Sobre o teatro de marionetes, para trazer à luz dois momentos convergentes com o 'Ma' e que podem auxiliar a indicar caminhos pela busca do senso de equilíbrio.

a. Suspensão: Proposta de suspensão distinta de Le Breton (2016), a noção de suspensão para Kleist parte da relação da marionete e do manipulador com o centro de gravidade de cada movimento dos corpos (marionete e manipulador). Por ser a marionete em si anti-gravitacional, segundo Kleist, cada movimento possui um centro de gravidade, diferente daquele relacionado com as leis da física sobre os corpos gravitacionais. Isto porque a marionete, ao contrário do bailarino (humano) é desprovido de intencionalidade e, para tanto, desprende esforço somente quando necessário, estabelecendo nos intervalos entremovimentos uma suspensão espaço-temporal sem tensionamento corporal, o que lhe confere a condição de atenção suficiente para responder a todos os estímulos prontamente, sejam estes estímulos oriundos das forças externas ou enquanto reverberação do movimento em seu próprio corpo. O que confere leveza e graciosidade à marionete são os intervalos entre o tensionamento e relaxamento, entre a consciência e a intencionalidade. Assim como em Ma, a suspensão em Kleist adquire um caráter transitório, momentâneo, temporário, que clama por uma pausa para o emprego da eficiência corporal e psíquica com o mínimo de esforço. É dizer que mais que uma fuga, a suspensão em Kleist refere-se a um nível de máxima (in)consciência responsiva.

b. Inocência: Outro aspecto que consideramos relevante para a aproximação do Ma com as marionetes de Kleist é o estado de inocência. Ao apresentar 
uma parábola do urso esgrimista, Kleist referenda a habilidade de precisão do urso de distinguir um ataque de uma finta e podemos perceber que esta "habilidade" do urso não se refere a um treinamento especializado que o permite distinguir entre o golpe real e não-real, mas conforme pondera Gumbrecht, é “justamente por não ter a capacidade de diferenciar entre o fingido e o real, ele [urso] é gracioso e um bom esgrimista" (GUMBRECHT, 2012, p.112). Ao desprender energia apenas nos momentos vitais da batalha, o estado de inocência do urso lhe confere maior destreza e calma. Neste sentido, podemos considerar que o estado de inocência em Kleist se relaciona diretamente com a capacidade de agir pelo filtro da percepção. Ao contrário do urso, o esgrimista, por valer-se de pré-julgamentos, multiplica seu campo de atuação entre racionalizações dos possíveis movimentos que o urso possa vir a executar, inibindo todas as possibilidades de vislumbrar os "entre-espaços", o "vazio" emanado pelo urso. Procurando o sentido em cada instante, esquivou-se de sentir.

Para além das questões teológicas ou mesmo poéticas que possam ser suscitadas, refletir sobre a preservação ou recuperação do estado de inocência enquanto faculdade sensível do humano para o retorno do senso de equilíbrio do sujeito, significa conferir uma ampla consciência corporal numa relação harmoniosa entre o pensar e o sentir.

Essas duas qualidades, a suspensão e a inocência, dentre várias outras que poderiam ser expressas para qualificar e tornar compreensível a potência do vazio em Ma, se presentificam em distintos aspectos da cultura japonesa², ao intentar compreender e representar o "vazio" através da necessidade de se alcançar uma plenitude perceptiva.

Essas experiências despertam o que Gumbrecht denomina de "crises da experiência estética", "uma vez que ela se opõe ao fluxo da nossa experiência cotidiana, os momentos da experiência estética se parecem com pequenas crises" (2006, p.51).

As "crises", que a potência do vazio desperta através da experiência estética, elucidam e enfatizam a terceira categoria proposta por Gumbrecht, por promover uma "mudança pré-consciente entre planos situacionais diferentes que, nesses casos, produzem a contiguidade - sempre excepcional - entre a experiência estética e o cotidiano" (GRUMBRECHT, 2006, p. 59). Ou seja, possibilitam, mesmo que momentaneamente, sair da inércia anestésica do cotidiano e fomentar a "ampliação de si" (FERRY, 2009) por possibilitar a autorreflexão de modo epifânico - "de uma forma complexa, corpórea e temporalizada" (GUMBRECHT, 2006, p. 60).

\section{Considerações finais}

Ao intentar as oscilações de experiência e de verdade, vislumbramos pela perspectiva da Midiatização, da Semiótica da Percepção, da Experiência Estética e da Antropologia

2 Como na literatura, arquitetura, fotografia, caligrafia, dança, música, produções audiovisuais, artes marciais, entre outros. 
do Corpo e dos Sentidos, meios de compreender as lógicas que, de certo modo, reconfiguram um modo de ser e viver do homem na contemporaneidade que desperta a tentação de reclusão social e de si mesmo.

Conforme argumenta Gumbrecht (2012, p. 118), "a ambição de constantemente transformar o mundo, ou de ter de fazer história, é uma ambição típica apenas das culturas de sentido. Em uma cultura de presença, porém, a autorreferência humana procura encontrar o seu próprio lugar dentro do mundo das coisas."

Diante do paradoxo da existência humana apresentado, a necessidade emergente de novas concepções de autorreferencialidade tomam destaque, como forma de resgate e aprendizagem de novas formas de sensibilidade para pulsar uma nova consciência que reposicione o corpo no tempo e no espaço.

Portanto, o corpo perceptivo e percebido, enquanto nossa primordial referência espaço-temporal, oscila entre duas visões, na contemporaneidade: a perspectiva de ser parte de um mundo real - localizado lá fora - e a perspectiva de ser um princípio de unificação do sujeito da experiência. Isto posto, admitimos que o corpo ubíquo, na atualidade, não pode mais ser apreendido somente a partir dele mesmo; sua presença perceptiva e extensiva ocorre, agora, em todas as possíveis extensões vinculadas em sua experiência corpo-ambiente-movimento.

E neste processo extensivo, recobrar o direito de uma pausa para suspender-se do cotidiano e apreender as coisas do mundo através do movimento, torna-se um ato emancipatório para desvelar a própria graciosidade como forma de resistência aos tempos de crise perceptiva.

Graciosidade confere o elemento 'sentir-se bem (of feeling good) justamente por não portar outra intencionalidade mediada pela razão.

Esse sentimento [sentir-se bem] parece ter sua origem na experiência de que o corpo é capaz de um comportamento completo que a consciência não consegue permitir ou controlar. Nisso consiste a euforia: perceber-se durante a dança que é possível; produzir uma complexidade de movimentos com o corpo que seria impossível se a consciência participasse demais desse jogo. (GUMBRECHT, 2012, p. 110)

Conforme alerta o cineasta Miyazaki, "what really matters is the underlying emotions - that you never let go of those."3 (EBERT, 2012, online). Isto porque "a antropologia dos sentidos repousa sobre a ideia de que as percepções sensoriais não dependem somente de uma fisiologia, mas em primeiro lugar de uma orientação cultural deixando uma margem à sensibilidade individual" (LE BRETON, 2016, p. 14).

Diante do tensionamento entre um passado dominado por um campo de experiências e um futuro que se apresenta como um horizonte de perspectivas (KOSELLECK, 2006),

3 "O que realmente importa são as emoções subjacentes - você não deve abandoná-las" (Tradução nossa). 
conceber o presente por meio da percepção instaura um novo paradigma de pensar o mundo e com ele reconfigurar o modo de ser, viver e percebê-lo, ao defrontarmos com o desafio de transformá-lo e nos transformarmos de sensível em inteligível.

Gisele Miyoko ONUKI I é doutoranda e mestre em Comunicação e Linguagens pela Universidade Tuiuti do Paraná (UTP) e professora da Universidade Estadual do Paraná (UNESPAR). É membro do GP TECA - Tecnologia: Experiência, Cultura e Afetos da UTP/CNPq e do GP NatFap - Núcleo de Arte e Tecnologia da FAP (UNESPAR/CNPq). É bolsista PROSUP CAPES.

gionuki@gmail.com

Cristiane Wosniak I é doutora e mestre em Comunicação e Linguagens pela Universidade Tuiuti do Paraná - UTP e professora Adjunta da Universidade Estadual do Paraná (UNESPAR). É líder do GP CineCriare - Cinema: criação e reflexão (UNESPAR/CNPq) e membro do GP GRUDES - Desdobramentos Simbólicos do Espaço Urbano em Narrativas Audiovisuais (UTP/CNPq).

cristiane_wosniak@yahoo.com.br

\section{Referências}

BAITELLO JUNIOR, N. A era da iconografia: reflexões sobre a imagem, comunicação, mídia e cultura. São Paulo: Paulus, 2014.

BARBOSA, M. O presente e o passado como processo comunicacional. In: Revista Matrizes, v. 5, $\mathrm{n}^{\circ} 2$, p. 145-155. <www.matrizes.usp.br/index.php/matrizes/article/view/253>. Acesso em 30 jun. 2018.

BENJAMIN, W. Sobre alguns temas em Baudelaire. Col. Os Pensadores. São Paulo: Abril Cultural, 1975.

EBERT, R. Hayao Miyazaki Interview. Roger Ebert Interviews, 2012. Disponível em https://www. rogerebert.com/interviews/hayao-miyazaki-interview. Acesso em 15 mai. 2018.

FERRY, L. Kant: uma leitura das três críticas. Rio de Janeiro: Difel, 2009.

GEERTZ, C. A interpretação das culturas. Rio de Janeiro: LTC, [1989] 2011.

GUMBRECHT, H.U. Nosso Amplo Presente. OTempo e a Cultura Contemporânea. São Paulo: Editora UNESP, 2015.

2010.

Produção de Presença: o que o sentido não consegue transmitir. Rio de Janeiro: Contraponto,

Graciosidade e estagnação: ensaios escolhidos. Rio de Janeiro: Contraponto, 2012. 
. Pequenas críticas. Experiência estética nos mundos cotidianos. In: GUIMARÃES, C. et al (orgs.). Comunicacão e Experiência Estética. Belo Horizonte: Ed. UFMG, 2006, p. 50-63.

HAROCHE, C. A condição sensível: formas e maneiras de sentir no Ocidente. Rio de Janeiro: Contra Capa, 2008.

HEPP, A.; HASEBRINK, U. Interação humana e configurações comunicativas: transformações culturais e sociedades midiatizadas.In: Revista Parágrafo, São Paulo, v. 2, n. 3, p. 75-89, jul./dez. 2015. Disponível em <http://www.revistaseletronicas.fiamfaam. br/index.php/recicofi/article/view/333/341>. Acesso em 26 mai, 2018.

. As configurações comunicativas de mundos midiatizados: pesquisa da midiatização na era da "mediação de tudo". In: Revista Matrizes, São Paulo, v. 8, n. 1, p. 45-64. Disponível em <http://www. andreas-hepp.name/wp-content/uploads/2017/10/hepp-2014-873.pdf >. Acesso em 26 mai, 2018.

KLEIST, H. von. Sobre o Teatro de Marionetes. 2a. ed. Rio de Janeiro: 7Letras, 2015.

KOSELLECK, R. Futuro Passado - contribuição à semântica dos tempos históricos. Rio de Janeiro: Contraponto, 2006.

LE BRETON, D. Desaparecer de sí - una tentación contemporánea. Madrid: Siruela, $2016 a$.

Antropologia dos Sentidos. Petrópolis, RJ: Vozes, $2016 \mathrm{~b}$.

LISPECTOR, C. A Paixão Segundo G.H. Rio de Janeiro: Rocco, 2009.

NANCY, J-L. Arquivida do senciente e do sentido. São Paulo: Iluminuras, 2014, p. 15-27.

OKANO, M. M. A estética do "entre". In: Revista USP n. 100, São Paulo. Ed. Dez/Jan/Fev 20132014, p. $150-164$.

RIES, B. E.; RODRIGUES, E. W. (orgs). Psicologia e educação: fundamentos e reflexões. Porto Alegre: EDIPUCRS, 2004.

SANTAELLA, L. A percepção: uma teoria semiótica. 2.ed. São Paulo: Experimento, 1998.

Percepção: fenomenologia, ecologia, semiótica. São Paulo: Cengage Learning, 2012.

SANTIN, S. Educação Física: Outros caminhos. Porto Alegre: Escola Superior de Teologia e Espiritualidade Franciscana, 1990.

TALO-HUGON, C. A estética: história e teorias. Lisboa: Texto \& Grafia, 2009.

WILLIAMS, R. Cultura e Sociedade. Petrópolis, RJ: Vozes, [1969] 2011. 